\title{
Karakteristik ibu balita dalam pemantauan pertumbuhan dan perkembangan balita
}

\author{
Susilawati ${ }^{1 *}$ \\ ${ }^{1}$ Program Studi D3 Kebidanan, STIKES AI-Irsyad Al-Islamiyyah, Cilacap - Indonesia
}

\begin{abstract}
In monitoring the growth and development of children, the role of parents is very important. Early detection by parents can identify $1-6 \%$ of children who have developmental disorders. Parents who did not monitor their child's growth and development were $34.3 \%$. It causes many children whose growth and development have not been observed. The incidence rate of developmental disorders in children is known to be around $33.5 \%$. The purpose of this study was to determine the characteristics of mothers of children under five in monitoring the growth and development of infants in Pusksmas Babakan Sari Bandung City. Descriptive research design with cross-sectional approach. This study used Accidental Sampling, as many as 53 mothers of children under five-data analysis using univariate analysis. The results showed that the characteristics of mothers of children under five were mostly at the age of 20 - 35 as many as 30 mothers (56.6\%), high school education as 29 mothers (54.8\%), family income with a high category of 27 mothers (50.9\%), having children $\geq 2$ as many as 37 mothers (69.8\%), and not working as many as 44 mothers $(83 \%)$.
\end{abstract}

Keywords: mothers of children; characteristics; growth; development

Dalam pemantauan pertumbuhan dan perkembangan anak peran orangtua sangat penting. Deteksi dini oleh orangtua dapat mengidentifikasi $1-6 \%$ anak yang mengalami gangguan tumbuh kembang. Orangtua yang tidak melakukan pemantauan tumbuh kembang anak sebanyak $34,3 \%$. Hal ini menyebabkan masih tingginya anak yang belum terpantau tumbuh kembangnya. Angka kejadian gangguan perkembangan pada anak diketahui sekitar 33,5\%. Tujuan penelitian ini untuk mengetahui karakteristik ibu balita dalam pemantauan pertumbuhan dan perkembangan balita di Puskesmas Babakan Sari Kota Bandung. Rancangan penelitian deskriptif dengan pendekatan cross-sectional. Sampel dalam penelitian ini menggunakan teknik accidental sampling, sebanyak 53 ibu balita. Analisis data menggunakan analisis univariat. Hasil penelitian menunjukkan karakteristik ibu balita sebagian besar pada umur 20 - 35 tahun sebanyak 30 ibu (56,6\%), pendidikan SMA sebanyak 29 ibu (54,8\%), pendapatan keluarga dengan kategori tinggi sebanyak 27 ibu (50,9\%), memiliki anak $\geq 2$ sebanyak 37 ibu (69,8\%), dan tidak bekerja sebanyak 44 ibu (83\%).

Kata Kunci: ibu balita; karakteristik; pertumbuhan; perkembangan

\footnotetext{
*Korespondensi Penulis: Susilawati (email: susilawatimdf@gmail.com), Jl. Cerme No. 24, Sidanegara, Cilacap Tengah, Cilacap, Jawa Tengah 53223.
} 


\section{Pendahuluan}

Pertumbuhan dan perkembangan pada anak adalah manifestasi dari berbagai interaksi yang kompleks antara faktor internal dan faktor eksternal (Richard et al., 2014). Pemberian gizi yang optimal selama masa bayi dan balita sangat penting karena pada periode ini ditandai cepatnya pertumbuhan dan perkembangan anak. Pada bayi memiliki kebutuhan substansi penting untuk energi dan nutrisi, karena untuk perkembangan perkembangan struktural dan fungsional otak (Emmett \& Jones, 2014). Pertumbuhan pada anak dapat diukur menggunakan antropometri. Instrumen antropometri yang digunakan untuk mengetahui pertumbuhan anak diantaranya adalah menggunakan standar WHO growth charts. Perkembangan anak terjadi pada beberapa aspek seperti perkembangan sosial, perkembangan emosional, dan perkembangan kognitif. Salah satu cara pengukuran perkembangan anak yang sistematis, komprehensif, efektif dan efisien adalah dengan Kuesioner Pra Skrining Perkembangan (KPSP) (Majnemer, 1998).

Tumbuh kembang anak berkorelasi dengan kepatuhan orangtua dalam proses pemantauan tumbuh kembang anaknya. Kepatuhan orangtua dalam pemantauan tumbuh kembang anak akan meningkat bila orangtua memiliki pendidikan yang lebih tinggi, umur yang lebih tua, memiliki tingkat pengetahuan yang tinggi, tingkat sosial ekonomi yang lebih tinggi, memiliki keterampilan yang lebih baik, dan juga semakin sering dalam berinteraksi dengan tenaga kesehatan (Niven, 2008). Hasil Riskesdas (2013) menunjukkan sebanyak 34,3\% orangtua tidak melakukan pemantauan tumbuh kembang, lebih tinggi dibandingkan hasil Riskesdas tahun 2007 se- banyak $25,5 \%$, yang menunjukkan masih tingginya anak yang belum terpantau tumbuh kembangnya. (Depkes RI, 2013).

Keterlambatan pertumbuhan dan perkembangan pada anak dapat diketahui sejak dini dengan program deteksi dini. Pendeteksian dini pada anak harus dilakukan sedini dan seakurat mungkin, sehingga apabila ada penyimpangan dapat diketahui lebih dini. Untuk tujuan pendeteksian ini, cek up rutin anak dan analisis harus dibuat secara hati-hati. Peran orangtua baik ibu maupun ayah dalam pemantauan pertumbuhan dan perkembangan anak sangat penting. Sehingga perlu kerjasama antara orangtua dan tenaga kesehatan untuk menentukan keakuratan tumbuh kembang anak (Glascoe \& Dworkin, 1995).

Data Riskesdas (2013) menyebutkan bahwa status gizi balita Indonesia menurut indikator $\mathrm{BB} / \mathrm{U}$ prevalensi berat kurang (gizi buruk dan gizi kurang) secara nasional adalah 19,6 persen. Terjadi peningkatan dibandingkan tahun 2010 sebesar 17,9\% dan tahun 2007 sebesar 18,4\% (Depkes RI, 2013). Angka kejadian gangguan perkembangan pada anak diketahui sekitar $33,5 \%$ anak, dimana $22,1 \%$ anak mengalami gangguan perkembangan dan $11,4 \%$ anak mengalami perkembangan yang meragukan (Petersen et al., 2009). Gangguan perkembangan pada anak di Indonesia adalah keterlambatan atau gangguan dalam perkembangan bicara $46,8 \%$ dan perkembangan gerak yang terlambat $30,9 \%$. Prevalensi gangguan perkembangan pada anak di Indonesia belum teridentifikasi secara nasional (Tjandrajani et al., 2016).

Beberapa penelitian menyebutkan hasil gangguan perkembangan pada anak seperti prevalensi gangguan perkembangan pada anak di 
Kabupaten Bandung diketahui terdapat 9,78\% anak mengalami perkembangan yang meragukan (Gunawan et al., 2011). Beberapa anak dapat mengalami keterlambatan pertumbuhan dan perkembangan yang memerlukan program penanganan supaya bisa beradaptasi untuk bisa mencapai tingkat perkembangan diumurnya tersebut (Chamidah, 2009; Figueroa, 2012). Pemantauan tumbuh kembang anak sangat memerlukan partisipasi keluarga, dengan deteksi dini oleh orangtua dapat mengidentifikasi 1- $6 \%$ anak yang mengalami gangguan tumbuh kembang.

Studi pendahuluan yang dilakukan pada salah satu Puskesmas Kota Bandung menyatakan bahwa cakupan pelaksanaan pemantauan pertumbuhan dam perkembangan anak balita sekitar 75\%, dilakukan pada kelompok PAUD, Sekolah Taman Kanak-kanak dan di Puskesmas. Data tersebut juga didukung dari hasil wawancara dengan kader kesehatan yang menyatakan bahwa pelaksanaan pemantauan dan perkembangan anak balita belum maksimal. Hal ini disebabkan komponen penilaian KPSP tidak semuanya dinilai, hanya komponen-komponen tertentu saja yang dianggap paling menonjol seperti bicara dan motorik. Berdasarkan proses pemantauan perkembangan tersebut, mengakibatkan tidak terdokumentasikannya masalah gangguan perkembangan bayi dan anak di wilayah kerja Puskesmas Babakan Sari Kota Bandung.

\section{Metode}

Rancangan penelitian ini adalah deskriptif dengan pendekatan waktu Cross Sectional. Penelitian dilaksanakan di Puskesmas Babakan Sari Kota Bandung. Sampel dalam penelitian ini menggunakan teknik accidental sampling se- banyak 53 ibu balita. Pengumpulan data menggunakan data primer berupa kuesioner yang terdiri dari pertanyaan terkait karakteristik responden meliputi umur ibu, pendidikan ibu, pendapatan keluarga, jumlah anak, dan status bekerja. Analisis data menggunakan analisis univariat.

\section{Hasil dan Pembahasan}

Penelitian dilaksanakan di Puskesmas Babakan Sari, menggunakan data primer pada ibu balita tahun 2017. Adapun hasilnya dapat dilihat melalui Tabel 1.

\section{Karakteristik Ibu Balita dalam Pemantauan Pertumbuhan dan Perkembangan Balita berdasarkan Umur Ibu}

Tabel 1 menunjukkan sebagian besar ibu berumur 20 - 35 tahun yaitu sebanyak $30 \mathrm{ibu}$ $(56,6 \%)$, kedua terbanyak kelompok umur $>35$ tahun yaitu sebanyak 21 ibu (39,3\%), dan sebagian kecil kelompok umur $<20$ tahun yaitu sebanyak 2 ibu (3,7\%).

Hasil penelitian ini memiliki hasil rata-rata umur yang hampir sama seperti penelitian Yeung, Linver dan Brooks-gunn (2002), tentang pangaruh pendapatan keluarga terhadap perkembangan anak yang menunjukkan ratarata umur responden ibu pada usia 32,6 $\pm 8,38$ tahun.

Umur seseorang juga dapat menggambarkan dari kematangan seseorang dalam menentukan segala sesuatu dari kehidupannya. Semakin usia mereka bertambah semakin matang pula mereka dalam menentukan suatu pemilihan sesuatu. Kementerian Kesehatan telah mengajur- 
Tabel 1. Distribusi Frekuensi Karakteristik Ibu Balita dalam Pemantauan Perumbuhan dan Perkembangan Balita

\begin{tabular}{|c|c|c|c|}
\hline No & Karakteristik & Frekuensi & Prosentase (\%) \\
\hline & Umur Ibu & & \\
\hline 1 & $<20$ tahun & 2 & 3,8 \\
\hline 2 & $20-35$ tahun & 30 & 56,6 \\
\hline \multirow[t]{2}{*}{3} & $>35$ tahun & 21 & 39,6 \\
\hline & Pendidikan & & \\
\hline 1 & SD & 6 & 11,3 \\
\hline 2 & SMP & 13 & 24,5 \\
\hline 3 & SMA & 29 & 54,8 \\
\hline \multirow[t]{2}{*}{4} & PT & 5 & 9,4 \\
\hline & Pendapatan Keluarga & & \\
\hline 1 & Rendah & 26 & 49,1 \\
\hline \multirow[t]{2}{*}{2} & Tinggi & 27 & 50,9 \\
\hline & Jumlah Anak & & \\
\hline 1 & 1 & 16 & 30,2 \\
\hline \multirow[t]{2}{*}{2} & $\geq 2$ & 37 & 69,8 \\
\hline & Status Bekerja & & \\
\hline 1 & Bekerja & 9 & 17 \\
\hline 2 & Tidak bekerja & 44 & 83 \\
\hline
\end{tabular}

kan agar wanita hamil sesuai dengan usia subur yang aman untuk hamil di Indonesia yaitu antara umur 20 sampai dengan 35 tahun, karena pada saat umur tersebut selain aman untuk hamil juga mengurangi angka kejadian gangguan pertumbuhan dan perkembangan pada anak yang dilahirkan, serta menghindarkan kematian ibu dan anak (Polit \& Beck, 2008).

Umur ibu di rentang 30-an dianggap sudah matang, maka saat mendidik dan merawat anak sudah lebih siap dibandingkan ibu yang berumur 20-an, pada rentang umur 30-an ibu dianggap mampu mengendalikan emosi dengan baik, hal ini berdampak baik bagi perkembangan anak karena dapat menempatkan dan mengajarkan emosi dengan baik saat mendidik, ibu di rentang umur 30-an sudah mulai memikirkan gaya hidup sehat untuk umur yang lebih panjang, hal ini menjadikan pola yang sama saat memberikan nutrisi pada anak sehingga anak ikut sehat dan nutrisi untuk pertumbuhannya terpenuhi dengan baik. Selain itu ibu di rentang umur 30-an lebih fokus pada kesejahteraan dan pendidikan anak, sehingga anak lebih terawat dengan baik. Perhitungan finansial yang lebih mapan dan bagus membuat ibu rentang umur 30 -an tidak ragu untuk memberikan produk terbaik untuk anaknya, hal ini juga berpengaruh besar pada terjaminnya perkembangan anak.

\section{Karakteristik Ibu Balita dalam Pemantauan Pertumbuhan dan Perkembangan Balita berdasarkan Pendidikan Ibu}

Tabel 1 menunjukkan sebagian besar berpendidikan SMA yaitu sebanyak 29 ibu (54,8\%), kedua terbanyak pendidikan SMP yaitu sebanyak 13 ibu (24,5\%), ketiga terbanyak pendidikan SD 
yaitu sebanyak 6 ibu $(11,3)$ dan sebagian kecil pendidikan PT yaitu sebanyak 5 ibu $(9,4 \%)$.

Hasil penelitian ini memiliki hasil kategori pendidikan yang hampir sama seperti penelitian Sugihartiningsih dan Vanara (2014) di Semarang tentang Hubungan Tingkat Pengetahuan lbu dengan Kepatuhan Mengikuti Kegiatan Posyandu Balita Di Posyandu Wijaya Kusuma VI Desa Jombor Kabupaten Semarang dari 43 responden diketahui $60,4 \%$ responden berpendidikan SMA, 14\% berpendidikan Diploma, sedangkan 25.6\% responden berpendidikan Sarjana.

Hasil penelitian Ariani dan Yosoprawoto (2012) di Malang, Jawa Timur, Indonesia tentang usia anak dan pendidikan ibu sebagai faktor risiko gangguan perkembangan anak diketahui bahwa terdapat hubungan yang signifikan antara tingkat pendidikan ibu dengan kejadian gangguan perkembanbangan anak $(O R=3,44$; nilai $p=$ 0,004). Penelitian Semba et al. (2008) di Indonesia dan Kamboja tentang anak yang mengalami stunting dan normal diketahui tingkat pendidikan ibu berhubungan dengan kejadian gangguan pertumbuhan stunting pada anak (nilai $p<0,001$ ). Diketahui bahwa tingkat pendidikan ibu merupakan faktor resiko anak mengalami kejadian gangguan pertumbuhan stunting (OR: 0,956; Cl 95\%: 0,950-0,961).

Penelitian Chen dan Li (2009) juga menunjukkan bahwa terdapat pengaruh yang signifikan antara tingkat pendidikan ibu terhadap pertumbuhan anak dan tingkat nutrisi anak. Penelitian ini menunjukkan bahwa terdapat hubungan yang sangat bermakna antara tingkat pendidikan ibu terhadap tingkat kesehatan anak, tingkat pendidikan ibu sangat berhubungan sekali dengan kesehatan anak, status nutrisi anak dan status kematian anak. Sedangkan tingkat pendidikan ayah hanya berpengaruh terhadap tingkat kesehatan anak hanya separuh dari tingkat pendidikan ibu. Pada ibu yang memiliki tingkat pendidikan yang lebih tinggi (lama sekolah > 7 - 9 tahun) akan lebih mudah dalam menyerap informasi tentang tumbuh kembang anak termasuk cara mendidik dan mengasuh anak dengan baik, demikian juga ibu yang memiliki pendidikan yang lebih tinggi akan lebih mudah mengaplikasikan tindakan dalam pemberian nutrisi dan makanan yang baik terhadap anak, sehingga anak akan mengalami proses pertumbuhan dan perkembangan yang lebih baik. Sementara itu juga ibu yang memiliki pendidikan yang lebih tinggi akan memberikan stimulasi, rangsangan, pendidikan dan nutrisi yang terbaik sehingga akan memiliki resiko lebih rendah mengalami kesakitan dan juga kematian pada usia anak-anak.

\section{Karakteristik Ibu Balita dalam Pemantauan Pertumbuhan dan Perkembangan Balita berdasarkan Pendapatan Keluarga}

Tabel 1 menunjukkan sebagian besar memiliki pendapatan dengan kategori tinggi yaitu sebanyak 27 ibu $(50,9 \%)$ dan kedua terbanyak pendapatan keluarga kategori rendah yaitu sebanyak 26 (49,1\%).

Hasil penelitian ini sesuai dengan karakteristik penelitian yang dilakukan oleh Yeung, Linver dan Brooks-gunn (2002) yang mengidentifikasi tentang pengaruh pendapatan keluarga terhadap perkembangan anak menyebutkan dari 57 responden keluarga diketahui responden sebagian besar yang memiliki tingkat pendapatan rendah sebanyak 57\%. Penelitian ini mengidentifikasi tentang pengaruh pendapatan keluarga terhadap 
perkembangan anak menyebutkan terdapat pengaruh yang signifikan antara pendapatan keluarga dengan tingkat perkembangan anak dimana keluarga yang memiliki pendapatan yang lebih tinggi akan membelanjakan uang untuk proses pertumbuhan dan perkembangan anaknya nilai $p<0,001$ (Yeung et al., 2002).

Di Indonesia juga senada dengan penelitian di atas dimana penelitian Yanuarti, Rusmil, dan Effendi (2014) di Bandung, Indonesia juga menyampaikan bahwa terdapat perbedaan yang bermakna antara tingkat pendapatan keluarga (kategori kurang, menengah dan tinggi) dengan kejadian gangguan perkembangan bahasa dan visual-motor (nilai $p<0,001$ ), dimana keluarga dengan pendapatan rendah lebih beresiko memiliki anak mengalami gangguan perkembangan. Dari beberapa penelitian diatas menjelaskan bahwa pendapatan sangat berpengaruh dengan tingkat perkembangan anak, dimana keluarga yang memiliki tingkat pendapatan tinggi akan berusaha memenuhi kebutuhan nutrisi anak mulai dari masa kandungan hingga saat lahir, dimana saat lahir keluarga juga akan memenuhi kebutuhan anak mulai dari nutrisi hingga peralatan maupun permainan-permainan yang mendidik (edukatif) untuk anaknya tersebut.

Penelitian Prentice et al. (2006) menyebutkan bahwa keluarga yang memiliki pendapatan lebih tinggi akan memberikan nutrisi lebih untuk anaknya mulai dari masa dalam kandungan hingga masa anak-anak. Penelitian Desai dan Alva (1998) tentang pendidikan orangtua dan pendapatan keluarga terhadap prestasi anak, disebutkan bahwa orangtua dengan pendapatan yang lebih tinggi akan lebih mampu memberikan keperluan pada anak untuk meningkatkan prestasi anak seperti bahan bacaan yang menyenangkan, membeli sejumlah buku, memberikan peralatan kesenian, peralatan olah raga, permainan puzzle ataupun video game.

\section{Karakteristik Ibu Balita dalam Pemantauan Pertumbuhan dan Perkembangan Balita berdasarkan Jumlah Anak}

Tabel 1 menunjukkan sebagian besar memiliki anak $\geq 2$ yaitu sebanyak 37 ibu (69,8\%), dan sebagian kecil memiliki anak 1 yaitu sebanyak 16 $(30,2 \%)$.

Hasil penelitian ini sesuai dengan karakteristik penelitian yang dilakukan oleh Ertem et al. (2007) yang meneliti tentang tingkat pengetahuan ibu tentang perkembangan anak pada negaranegara berkembang diketahui sebanyak $54,4 \%$ memiliki anak 2 atau lebih. Penelitian Bang (2008) tentang analisis faktor resiko anak yang mengalami suspek keterlambatan perkembangan menjelaskan bahwa tidak terdapat hubungan yang signifikan antara anak pertama (1) dan anak yang kedua atau lebih $(\geq 2)$ dengan kejadian gangguan perkembangan anak (nilai $p=0,420$ ). Semua anak memiliki peluang sama untuk menjadi sehat serta juga memiliki peluang yang sama untuk mengalami gangguan, karena yang menjadi faktor resiko anak sehat-sakit sebagian besar adalah dari faktor orangtua (Emerson, 2003).

Studi oleh Engle dan Black (2008) menjelaskan bahwa orangtua merupakan faktor penentu kesehatan tumbuh kembang anak, maka perlu adanya program-program untuk orangtua, diantaranya adalah program pendidikan dan tambahan pengetahuan dalam mengasuh anak, dengan kualitas, frekuensi dan durasi yang semakin banyak. Serta perlunya program 
dukungan keluarga secara bersama-sama dalam hal kesehatan anak, nutrisi anak, sistem pendidikan anak dan pelayanan anak.

Studi Engle et al. (2007) yang lainnya menjelaskan bahwa beberapa strategi perlu dilakukan untuk mengurangi gangguan disabilitas dan meningkatkan development outcome pada negara dengan pendapatan rendah dan menengah. Diantaranya adalah perlunya pendidikan dan penambahan wawasan kepada orangtua terhadap pertumbuhan dan perkembangan anak, serta perlunya peningkatan ekonomi keluarga untuk memenuhi kebutuhan anak saat masa pertumbuhan. Disamping itu juga perlu adanya pembatasan kelahiran anak, pada keluarga-keluarga yang masuk dalam kategori pendapatan rendah untuk menghindari anak yang dilahirkan mengalami gangguan pertumbuhan dan perkembangan.

\section{Karakteristik Ibu Balita dalam Pemantauan Pertumbuhan dan Perkembangan Balita berdasarkan Status Bekerja}

Tabel 1 menunjukkan sebagian besar tidak bekerja yaitu sebanyak 44 ibu (83\%), dan sebagian kecil status bekerja yaitu sebanyak $9 \mathrm{ibu}$ (17\%).

Hasil penelitian ini memiliki hasil kategori status bekerja yang hampir sama seperti penelitian Ariani dan Yosoprawoto (2012) di Malang, Jawa Timur, Indonesia tentang Usia Anak dan Pendidikan Ibu sebagai Faktor Risiko Gangguan Perkembangan Anak, diketahui sebanyak $46,4 \%$ ibu bekerja dan sebanyak $53,4 \%$ ibu tidak bekerja. Penelitian Huston dan Aronson (2005), tentang pengaruh waktu pada ibu bekerja terhadap hubungan ibu dan anak (Mother-Child Relationships) dan perkembangan awal anak di Amerika menjelaskan bahwa terdapat perbedaan yang bermakna antara jumlah jam kebersamaan anak pada antara ibu yang bekerja dan yang tidak bekerja (nilai $p<0,001$ ), dan terdapat perbedaan yang bermakna antara interaksi sosial ibu dan anak antara ibu yang bekerja dan yang tidak bekerja (nilai $p<0,001$ ), hasil penelitian juga menunjukkan anak yang diasuh oleh ibu yang tidak bekerja lebih menunjukkan ekspresi bahasa dan perbendaharaan kata yang lebih banyak.

Ini sejalan dengan penelitian Gauthier dan DeGusti (2012) yang menyebutkan bahwa ibu yang tidak bekerja akan memiliki waktu lebih banyak bersama dengan anaknya dibanding ibu yang bekerja, selama waktu bersama ibu dan anak tersebut lebih memungkinkan ibu yang tidak bekerja untuk berinteraksi, bermain dan melakukan permainan yang mampu merangsang dan menstimulasi tumbuh kembang anaknya tersebut.

\section{Kesimpulan}

Karakteristik ibu balita dalam pemantauan pertumbuhan dan perkembangan balita di Puskesmas Babakan Sari berdasarkan umur ibu sebagian besar berada di rentang umur produktif, berpendidikan menengah atas, memiliki pendapatan dengan kategori tinggi, memiliki anak $\geq 2$ dan tidak bekerja. Hasil penelitian ini diharapkan bisa dijadikan bahan pertimbangan, tambahan pengetahuan dan orangtua untuk dapat mengaplikasikan pemantauan pertumbuhan dan perkembangan kepada anaknya, sehingga manakala terdapat gangguan atau keterlambatan dapat ditangani lebih dini.[] 


\section{Daftar Pustaka}

Ariani, A., \& Yosoprawoto, M. (2012). Usia anak dan pendidikan ibu sebagai faktor risiko gangguan perkembangan anak. Jurnal Kedokteran Brawijaya, 27(2), 118-121. https://doi.org/ 10.21776/ub.jkb.2012.027.02.13

Bang, K. (2008). Analysis of risk factors in children with suspected developmental delays on the Denver Developmental Screening Test. Adong Kanho Hakhoe chi; Journal of Korean Academy of Child Health Nursing, 14(3), 261268.

Chamidah, A. N. (2009). Deteksi dini gangguan pertumbuhan dan perkembangan anak. Jurnal Pendidikan Khusus, 4(3), 83-93. https://doi.org/10.21831/jpk.v4i3.789

Chen, Y., \& Li, H. (2009). Mother's education and child health: Is there a nurturing effect? Journal of Health Economics, 28(2), 413-426. https://doi.org/10.1016/j.jhealeco.2008.10.0 05

Depkes RI. (2013). Riset kesehatan dasar 2013.

Desai, S., \& Alva, S. (1998). Maternal education and child health: Is there a strong causal relationship? Demography, 35(1), 71-81.

Emerson, E. (2003). Mothers of children and adolescents with intellectual disability: Social and economic situation, mental health status, and the self-assessed social and psychological impact of the child's difficulties. Journal of Intellectual Disability Research, 47(4-5), 385399. https://doi.org/10.1046/j.1365-2788. 2003.00498.x

Emmett, P. M., \& Jones, L. R. (2014). Diet and growth in infancy: Relationship to socioeconomic background and to health and development in the Avon Longitudinal Study of Parents and Children. Nutrition Reviews, 72(8), 483-506. https://doi.org/10.1111/nure.12122
Engle, P. L., \& Black, M. M. (2008). The effect of poverty on child development and educational outcomes. Annals of the New York Academy of Sciences, 1136(1), 243-256. https://doi.org/10.1196/annals.1425.023

Engle, P. L., Black, M. M., Behrman, J. R., Cabral de Mello, M., Gertler, P. J., Kapiriri, L., Martorell, R., \& Young, M. E. (2007). Strategies to avoid the loss of developmental potential in more than 200 million children in the developing world. The Lancet, 369(9557), 229-242. https://doi.org/10.1016/S01406736(07)60112-3

Ertem, I. O., Atay, G., Dogan, D. G., Bayhan, A., Bingoler, B. E., Gok, C. G., Ozbas, S., Haznedaroglu, D., \& Isikli, S. (2007). Mothers' knowledge of young child development in a developing country. Child: Care, Health and Development, 33(6), 728-737. https:// doi.org/10.1111/j.1365-2214.2007.00751.x

Figueroa, A. (2012). Connecticut's guidelines for the development of infant \& toddler early learning: A handbook for caregivers of young children. Connecticut USA: Connecticut Department of Social Services.

Gauthier, A. H., \& DeGusti, B. (2012). The time allocation to children by parents in Europe. International Sociology, 27(6), 827-845. https://doi.org/10.1177/0268580912443576

Glascoe, F. P., \& Dworkin, P. H. (1995). The role of parents in the detection of developmental problems and behavioral problems. Pediatrics, 95(6), 829-836.

Gunawan, G., Fadlyana, E., \& Rusmil, K. (2011). Hubungan status gizi dan perkembangan anak usia 1-2 tahun. Sari Pediatri, 13(2), 142146. https://doi.org/10.14238/sp13.2.2011. 142-6

Huston, A. C., \& Rosenkrantz Aronson, S. (2005). Mothers' time with infant and time in 
employment as predictors of mother? Child relationships and children's early development. Child Development, 76(2), 467-482. https://doi.org/10.1111/j.1467-8624.2005. 00857.x

Majnemer, A. (1998). Benefits of early intervention for children with developmental disabilities. Seminars in Pediatric Neurology, 5(1), 62-69. https://doi.org/10.1016/S1071-9091(98) 80020-X

Niven, N. (2008). Psikologi kesehatan: Pengantar untuk perawat dan profesional. Jakarta: EGC.

Petersen, M. C., Kube, D. A., Whitaker, T. M., Graff, J. C., \& Palmer, F. B. (2009). Prevalence of developmental and behavioral disorders in a pediatric hospital. Pediatrics, 123(3), e490e495. https://doi.org/10.1542/peds.20082750

Polit, D. F., \& Beck, C. T. (2008). Nursing research: Generating and assessing evidence for nursing practice. Philadelphia: Lippincott Williams \& Wilkins.

Prentice, A., Schoenmakers, I., Ann Laskey, M., de Bono, S., Ginty, F., \& Goldberg, G. R. (2006). Symposium on 'Nutrition and health in children and adolescents' Session 1: Nutrition in growth and development Nutrition and bone growth and development. Proceedings of the Nutrition Society, 65(4), 348-360. https://doi.org/10.1079/PNS2006519

Richard, S. a., McCormick, B. J. J., Miller, M. a., Caulfield, L. E., \& Checkley, W. (2014). Modeling environmental influences on child growth in the MAL-ED cohort study: Opportunities and challenges. Clinical Infectious Diseases, 59(suppl_4), S255-S260. https://doi.org/10.1093/cid/ciu436
Semba, R. D., de Pee, S., Sun, K., Sari, M., Akhter, N., \& Bloem, M. W. (2008). Effect of parental formal education on risk of child stunting in Indonesia and Bangladesh: A cross-sectional study. The Lancet, 371(9609), 322-328. https://doi.org/10.1016/S01406736(08)60169-5

Stevens, J. H. (1984). Child development knowledge and parenting skills. Family Relations, 33(2), 237-244. https://doi.org/10.2307/583789

Sugihartiningsih, S., \& Vanara, D. S. (2014). Hubungan tingkat pengetahuan ibu dengan kepatuhan mengikuti kegiatan posyandu balita di Posyandu Wijaya Kusuma VI Desa Jombor Kabupaten Semarang. Profesi: Media Publikasi Penelitian, 11(1), 46-51. https://doi.org/10.26576/profesi.75

Tjandrajani, A., Dewanti, A., Burhany, A., \& Widjaja, J. A. (2016). Keluhan utama pada keterlambatan perkembangan umum di Klinik Khusus Tumbuh Kembang RSAB Harapan Kita. Sari Pediatri, 13(6), 373-377. https://doi.org/10.14238/sp13.6.2012.373-7

Yanuarti, H. P., Rusmil, K., \& Effendi, S. H. (2014). Environment as a risk factor in delayed development in premature, low-birthweight and mild asphyxia children. Pediatrics International, 56(5), 720-725. https://doi.org/10.1111/ped.12333

Yeung, W. J., Linver, M. R., \& Brooks-Gunn, J. (2002). How money matters for young children's development: Parental investment and family processes. Child Development, 73(6), 1861-1879. https://doi.org/10.1111/14678624.t01-1-00511 
The page was intentionally left blank. 